\title{
A process chain for integrating microfluidic interconnection elements by micro-overmoulding of thermoplastic elastomers
}

\author{
U M Attia*1 and J R Alcock ${ }^{2}$ \\ ${ }^{* 1}$ Building 56, Cranfield University, Wharley End, Cranfield, Bedfordshire, MK43 0AL, UK \\ E-mail: u.attia@cranfield.ac.uk \\ ${ }^{2}$ Building 61, Cranfield University, Wharley End, Cranfield, Bedfordshire, MK43 0AL, UK \\ E-mail: j.r.alcock@cranfield.ac.uk
}

\begin{abstract}
This paper presents a process chain for in-line integration of microfluidic interconnection elements by a variant of micro-injection moulding ( $\mu \mathrm{IM})$. A SEBS-based thermoplastic elastomer (TPE) was moulded over polymethylmethacrylate (PMMA) to produce a hybrid microfluidic structure with aspect ratio of 2 . The process chain implemented micromilling for fabricating micro-structured tool inserts, and $\mu \mathrm{IM}$ and micro-overmoulding was used for replication. A two-plate mould was used for moulding the substrate, whilst a three-plate mould with a replaceable insert was used for TPE overmoulding. The presented application was an interconnect system for a microfluidic device, which enabled direct fitting of standard tubes into microfluidic substrates. A leakage test showed that the interconnection was leak-proof within a range of flow rates between 0.32 and $0.62 \mathrm{ml} / \mathrm{min}$.
\end{abstract}

Keywords: micro-injection moulding, thermoplastic elastomers, micro-overmoulding, microfluidics, functional integration, interconnection

PACS codes: 81.16.-c, 81.05.Lg, 07.10.Cm, 85.85.+j, 87.85.Va, 81.20.Vj, 81.20.Wk

Submitted to: Journal of Micromechanics and Microengineering

\section{Introduction}

Micro-injection moulding ( $\mu \mathrm{IM}$ ) has evolved during the past decade to be one of the most important processes for high-volume fabrication of micro-components. Advantages of the process include replication fidelity, dimensional accuracy and wide variety of processable materials. The rapid developments introduced in $\mu \mathrm{IM}$ made it a very popular choice for high-volume applications, and it is currently used on a commercial scale for, e.g. some microfluidic applications [1].

The commercial use of the process is, nevertheless, limited to micro-components with relatively simple structures. This is because the current technology level of standard $\mu \mathrm{IM}$ does not provide the ability to in-line integration of functional elements, which is an increasing requirement for microcomponents with relatively complex structures. Therefore, process variants are being developed to expand the capabilities of $\mu \mathrm{IM}$ beyond simple replication to include, for example, functional integration [2]. 
A developing variant of $\mu \mathrm{IM}$ is micro-assembly injection moulding ( $\mu \mathrm{AIM})$, which is a process that allows for the assembly of hybrid micro-structures [3]. Similar to conventional moulding, $\mu$ AIM combines different processing aspects, such as movable elements, hard/soft combinations and hollow structures [4]. The process can involve a combination of different polymers or polymers with other materials $[5,6]$.

Combining polymers with elastomers is a well established process in conventional, macro-scale injection moulding, where the mechanical properties of elastomers (e.g. low tensile strength, high elongation at break and range of hardness values) make them suitable for applications such as gripping elements, gaskets, insulations and part aesthetics.

Unlike the case with macro-scale moulding, very little is available in the literature about $\mu$ IM of elastomers. A single experiment has been reported were thermoplastic polyurethanes were micromoulded as non-hybrid into high-aspect ratio structures [7]. In another paper, TPE was used for packaging an injection-moulded microfluidic device [8]. Here, a TPE foil was welded to Polypropylene (PP) substrates by post-processing. In these two cases, TPE was either micromoulded alone or assembled by post processing, but no prior work exists where micro-overmoulding was done with a TPE.

The presented process chain involves the use of a 3-plate mould for overmoulding. Micromoulding by a 3-plate mould has been reported in one experiment $[9,10]$ to fabricate a polyoxymethylene (POM) micro-gear and a polycarbonate (PC) lens array. The micro-gear mould had a gate diameter of $0.6 \mathrm{~mm}$, whilst the lens component had a gate diameter of $0.3 \mathrm{~mm}$. No prior work exists where 3-plate moulds with replaceable inserts where used for micro-over moulding.

This paper assesses the feasibility of a process chain for integrating functional structural elements in $\mu \mathrm{IM}$ using a thermoplastic elastomer. A micro-overmoulding process was used to micromould a TPE over a PMMA substrate using a 3-plate mould with replaceable inserts. The case study used to assess the process chain regards an interconnection system for attaching tubes into a 3-D microfluidic system.

Interconnection systems are usually produced by post-processing techniques, such as using adhesives or commercially available, usually expensive, ports. The selected case study is an example of how direct integration within micromoulding could decrease the time and cost of post-processing step, which can sometimes make up to $80 \%$ of the device manufacturing cost [11]. A review is available in the literature about current integration methods of interconnection elements by highvolume polymer replication methods [2]. 


\section{Experiments}

\subsection{Case study}

The case study presented in this paper is a building block in a laminated 3-D microfluidic device for blood/plasma separation. It consists of a substrate that has two outlets, one for a cell-rich phase and the other for the plasma-rich phase. A detailed description of the device functionality is available in the literature [12].

The original substrate was designed such that tubes are interconnected into outlets by adhesives in post-processing steps. A modified design, presented here, integrates an interconnection element by $\mu \mathrm{IM}$, into which tubes would be directly press-fitted. Figure 1 shows a schematic representation of the original and modified designs.

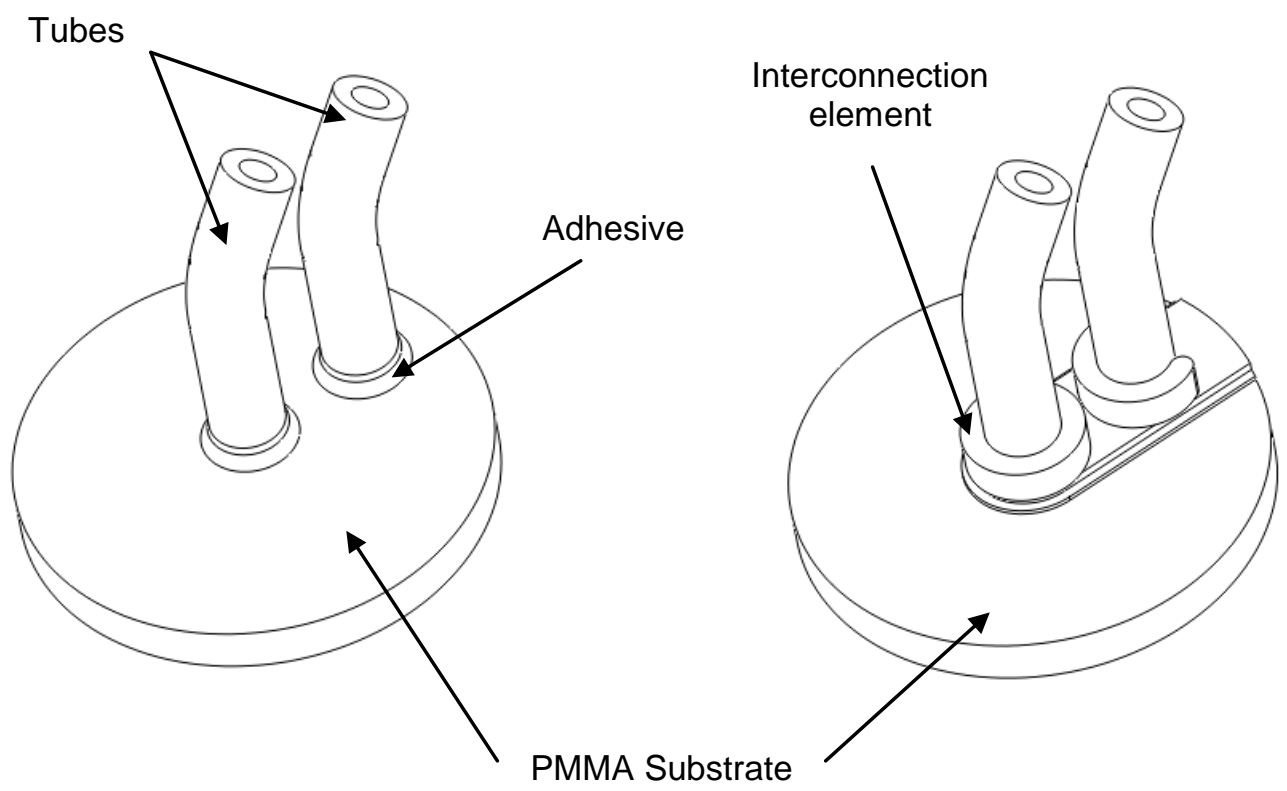

Figure 1. Two substrates with post-processed and integrated interconnection systems

\subsection{Part design}

The interconnection element was fabricated by micro-overmoulding, where TPE was moulded over a substrate made of PMMA. Figure 2 shows a half cross-section of the sample. The substrate had outer dimensions of $10 \mathrm{~mm}$ in diameter and $1 \mathrm{~mm}$ in thickness. One interconnect port is fully cylindrical along the diameter of the TPE element, whilst the other port is partially cylindrical along half the diameter. This was done to avoid interference between the mould cavity of partiallycylindrical port with the gate cavity which is adjacent to the port. Figure 8 , which shows the mould of the TPE component, illustrates that the partial cylindrical groove that corresponds to one of the TPE flanges will intersect with the gate opening if the grove is machined as a fully circular cylinder. 


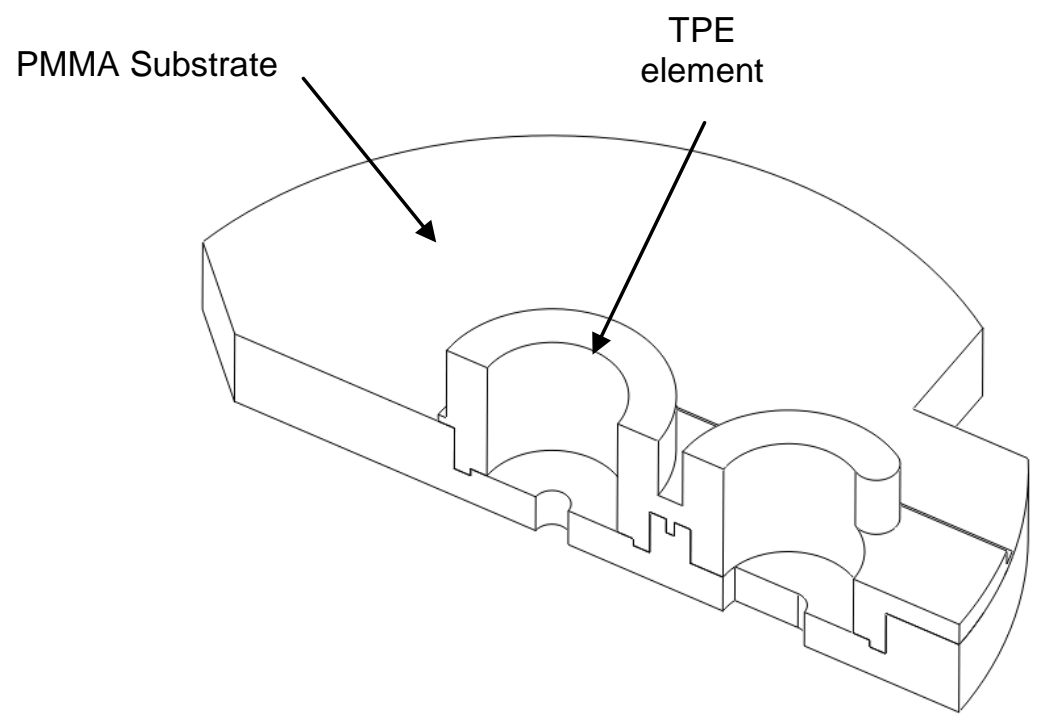

Figure 2. Half cross section of the interconnection system

Each port has a wall thickness of $500 \mu \mathrm{m}$ and a depth of $1.3 \mathrm{~mm}$, which makes the aspect ratio (AR) of the corresponding cavity in the mould equals to 2.6.

Figure 3 presents a CAD image of the PMMA substrate alone. The part was designed to receive the fluidic sample from the other layers of the device through $400-\mu$ m-diameter channels, which delivered the fluidic samples to the ports, where tubes were connected.

Some features have been introduced to the surface of the part to allow mechanical interlocking with the overmoulded TPE. They consist of channels of dimensions of $100 \mu \mathrm{m}$ width x $200 \mu \mathrm{m}$ depth $(\mathrm{AR}=2)$. Also, positioning marks were introduced to accurately position the substrate during overmoulding and restrict possible motion in the mould. 


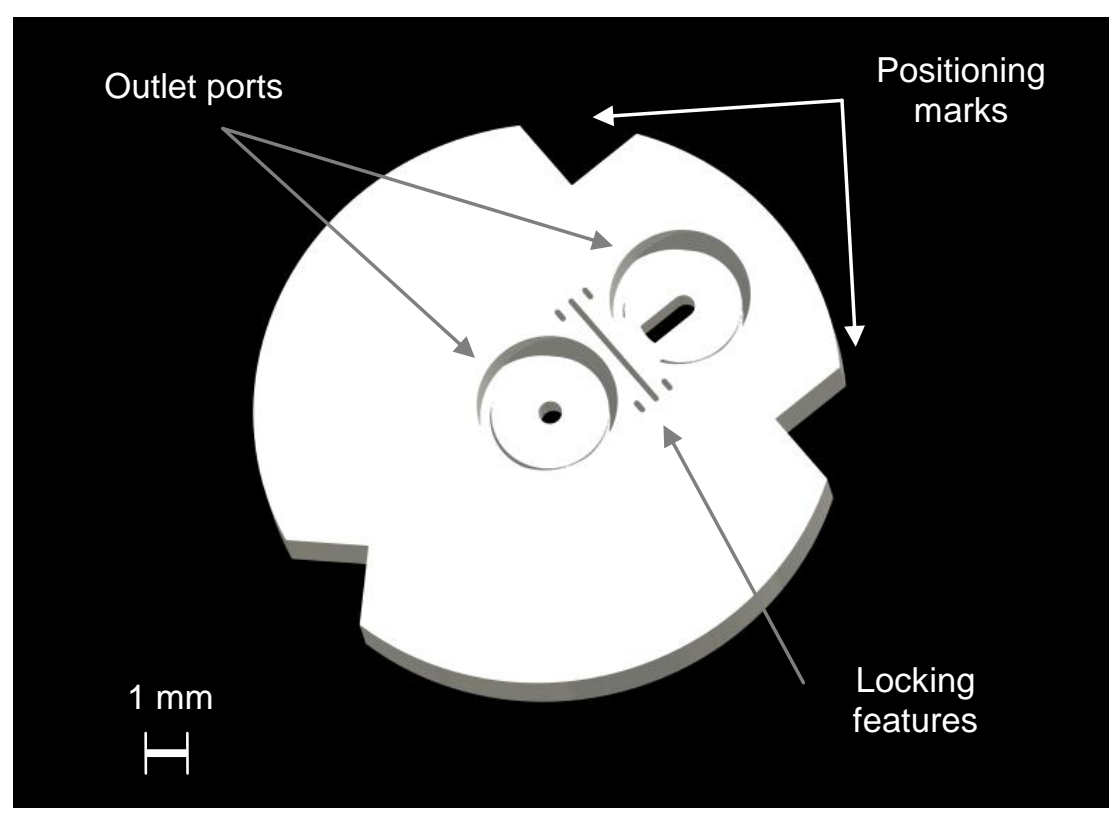

Figure 3. A CAD drawing of the PMMA substrate

\subsection{Mould design}

The moulding process took place in two stages, the first of which was the moulding of the PMMA substrate, whilst the second was the overmoulding of the TPE interconnection element. The first stage was done with a 2-plate mould, while the second stage was done with a 3-plate mould as detailed in the following sections.

2.3.1. Substrate mould design. The substrate mould consisted of a reconfigurable system, where micro-features were micro-milled in an aluminium insert, whilst the mould body was made of steel. This allowed for more flexibility in mould design and reduced micro-milling time and cost. The other side of the 2-plate mould was a flat steel plate. Figure 4 shows a diagram of the insert and figure 5 shows an SEM image of the micro-milled insert.

The micromilling sequence consisted of a roughening and finishing steps. Cutting tools of different diameters were used, the least of which was $100 \mu \mathrm{m}$. All cutting tools were tungsten-carbide, flat-end milling cutters. 


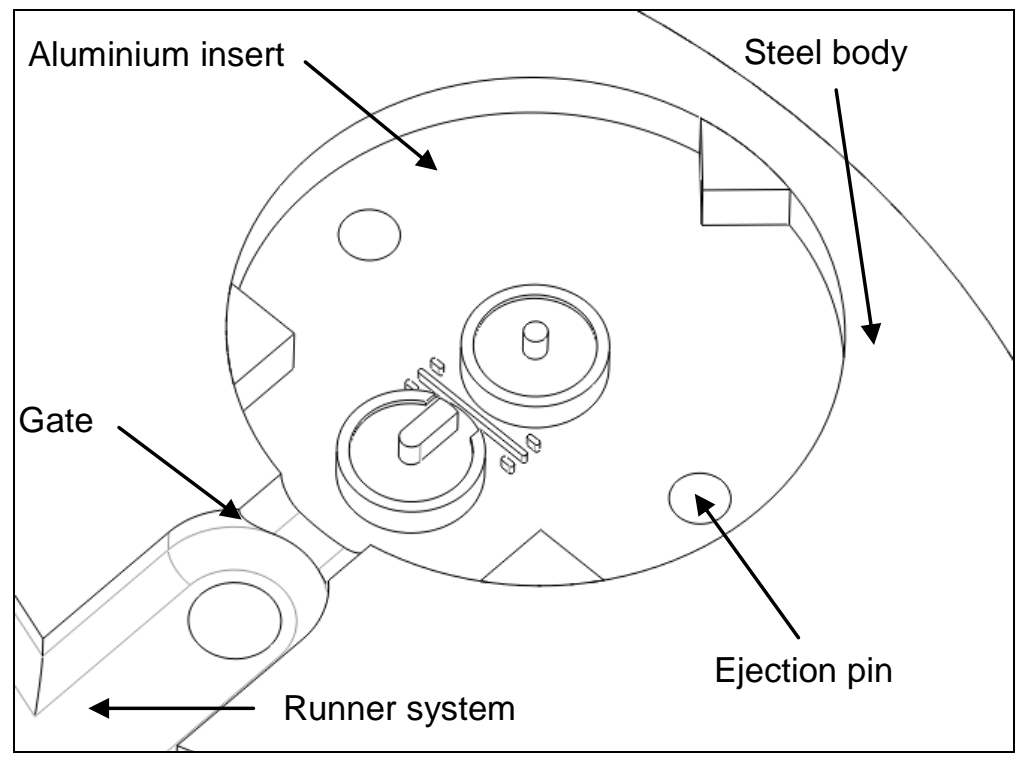

Figure 4. A CAD diagram of the reconfigurable mould

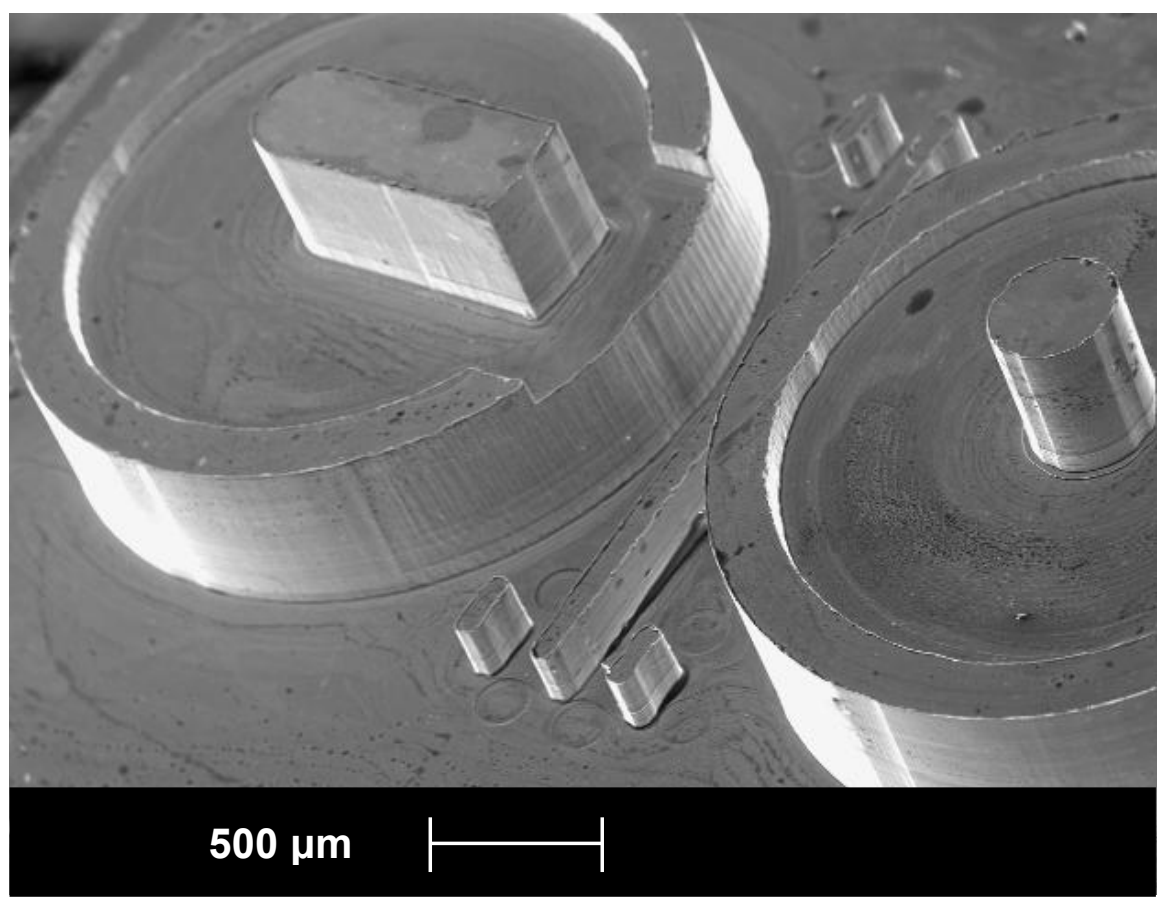

Figure 5. An SEM micrograph of the aluminium insert 
2.3.2. TPE mould design. The overmoulding design was relatively more complex in that the substrate and required features on both sides of the parting surface. A 3-plate mould with a replaceable insert was therefore implemented, where the PMMA substrate was positioned on the moving half of the mould, whilst the overmoulding took place on the middle (third) plate. The mould was designed with two cavities. Figure 6 presents a schematic diagram of the system, where, due to size limitations, only the reconfigurable parts are shown without the surrounding mould body (ejector pins were eliminated from the figure for simplicity).

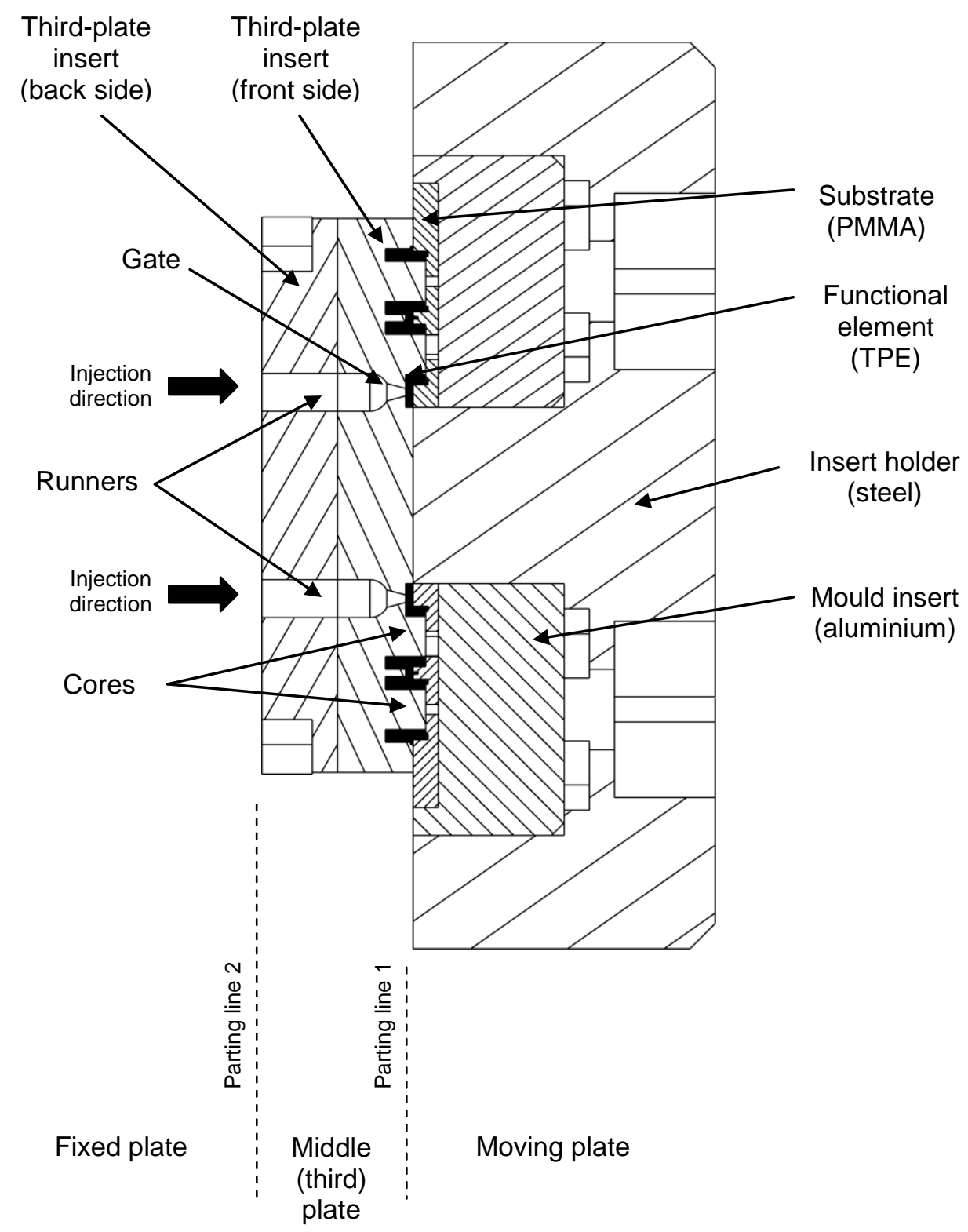

Figure 6. Cross-section of the 3-plate micromould 
In figure 6 , two parting lines define the 3 plates of the mould, namely a moving plate, a fixed plate and a middle, third plate. All parts were made from hardened tool steel except for the replaceable aluminium inserts. The third and moving plates were both two-cavity moulds.

The third plate was also designed with a replaceable steel insert, where features were produced by micro-milling. Due to the required geometry of the interconnection system, two cores were required for each part to form the cylindrical cavities, where interconnection tubes would be fitted into the port. As shown in figure 6, the four cores protruded beyond parting line 1 into the PMMA substrate. The standard steel inserts of the third plate had a thickness that made them flush with the parting surface (parting line 1). Therefore, the insert was redesigned into two halves, where the front half is thicker than the rest of the third plate, allowing for the milling of the protruding cores, as shown in the figure.

Figures 7 and 8 show a picture of the moving side and an SEM micrograph of the third-plate side of the 3-plate mould, respectively.

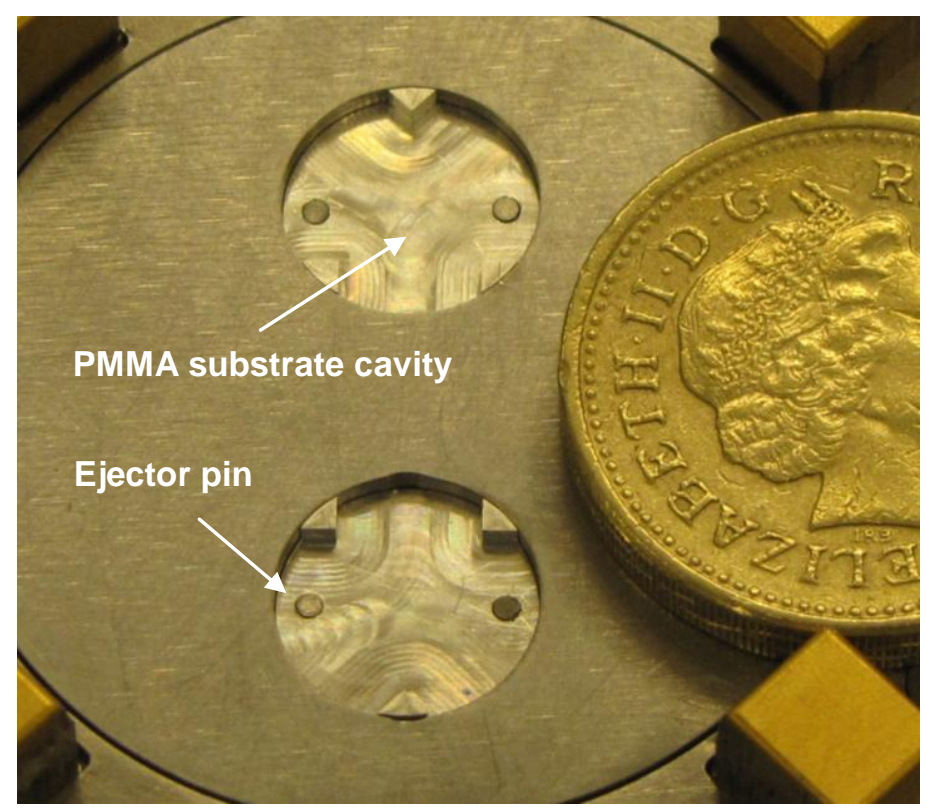

Figure 7. Moving-plate side of a 3-plate mould: cavities for holding PMMA substrates 


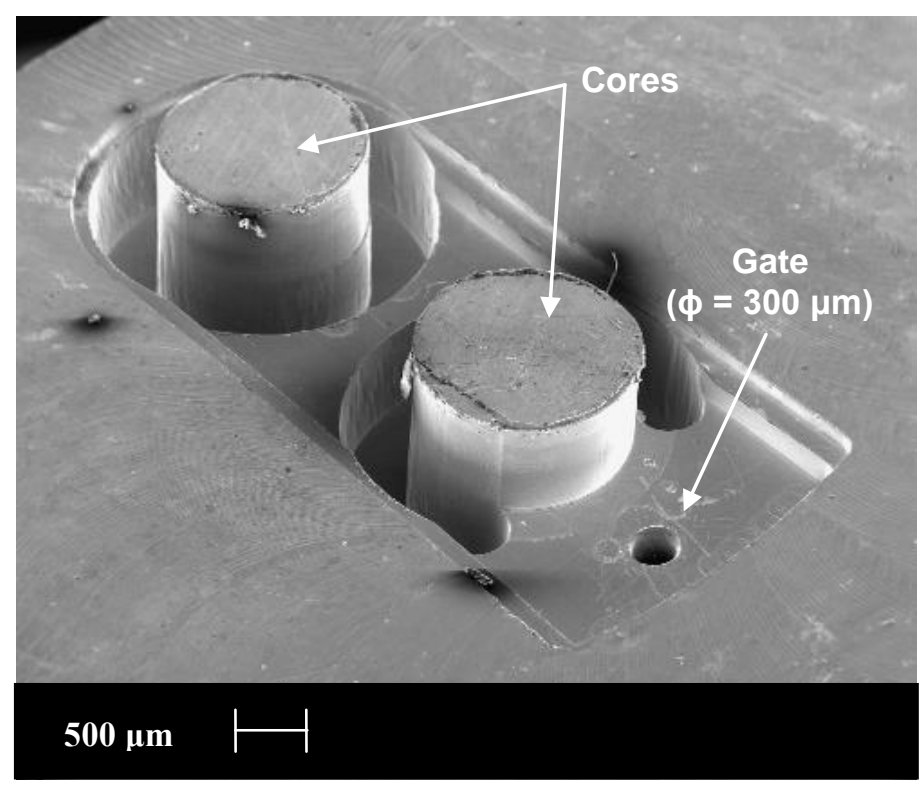

Figure 8. Third plate side of a 3-plate mould

Some features in figure 8 had to be redesigned in terms of their aspect ratios to be machinable by standard cutters. The gate holes shown in the figure were done by bespoke cutting tools. The tools were made with extended lengths relative to their cutting diameter to reach the required depth of cut with the required cutting diameter of $300 \mathrm{~mm}$.

\subsection{Micromoulding of hybrid components}

The micro-moulding process was undertaken as two stages. The first was the moulding of the PMMA substrates, and the second was the overmoulding of TPE to form the interconnection element. A high-flow PMMA grade was used in this experiment (VS-UVT from Altuglas). The TPE was a Styrene-Ethylene-Butylene-Styrene (SEBS) copolymer. The grade used (MEGOL SV/P from API) was selected for its adhesion compatibility with polar polymers, such as PMMA. This particular TPE grade has a tensile strength of $0.015 \mathrm{GPa}$ and elongation at break of $450 \%$. The micro-injection moulding machine was a Battenfeld Microsystems 50 and the micromilling machine was a KERN Evo. The following sections present the two stages of the process.

Table 1 shows the process conditions for the two stages: polymer-melt temperature $\left(\mathrm{T}_{\mathrm{p}}\right)$, mould temperature $\left(\mathrm{T}_{\mathrm{m}}\right)$, injection speed $\left(\mathrm{V}_{\mathrm{i}}\right)$, holding pressure $\left(\mathrm{P}_{\mathrm{h}}\right)$ and cooling time $\left(\mathrm{t}_{\mathrm{c}}\right)$.

Table 1. Processing conditions for PMMA and TPE.

\begin{tabular}{lccccc}
\hline & $\mathrm{T}_{\mathrm{p}}\left[{ }^{\circ} \mathrm{C}\right]$ & $\mathrm{T}_{\mathrm{m}}\left[{ }^{\circ} \mathrm{C}\right]$ & $\mathrm{V}_{\mathrm{i}}[\mathrm{mm} / \mathrm{s}]$ & $\mathrm{P}_{\mathrm{h}}[\mathrm{bar}]$ & $\mathrm{t}_{\mathrm{c}}[\mathrm{s}]$ \\
\hline Micro-moulding of PMMA & 260 & 84 & 200 & 300 & 4 \\
\hline Micro-overmoulding of TPE & 200 & 65 & 200 & 400 & 10 \\
\hline
\end{tabular}


The cycle times for $\mu \mathrm{IM}$ of PMMA and micro-overmoulding of the TPE were approximately 5 and 12 seconds, respectively.

\section{Results}

Figure 9 shows an SEM image of the replicated PMMA substrate.

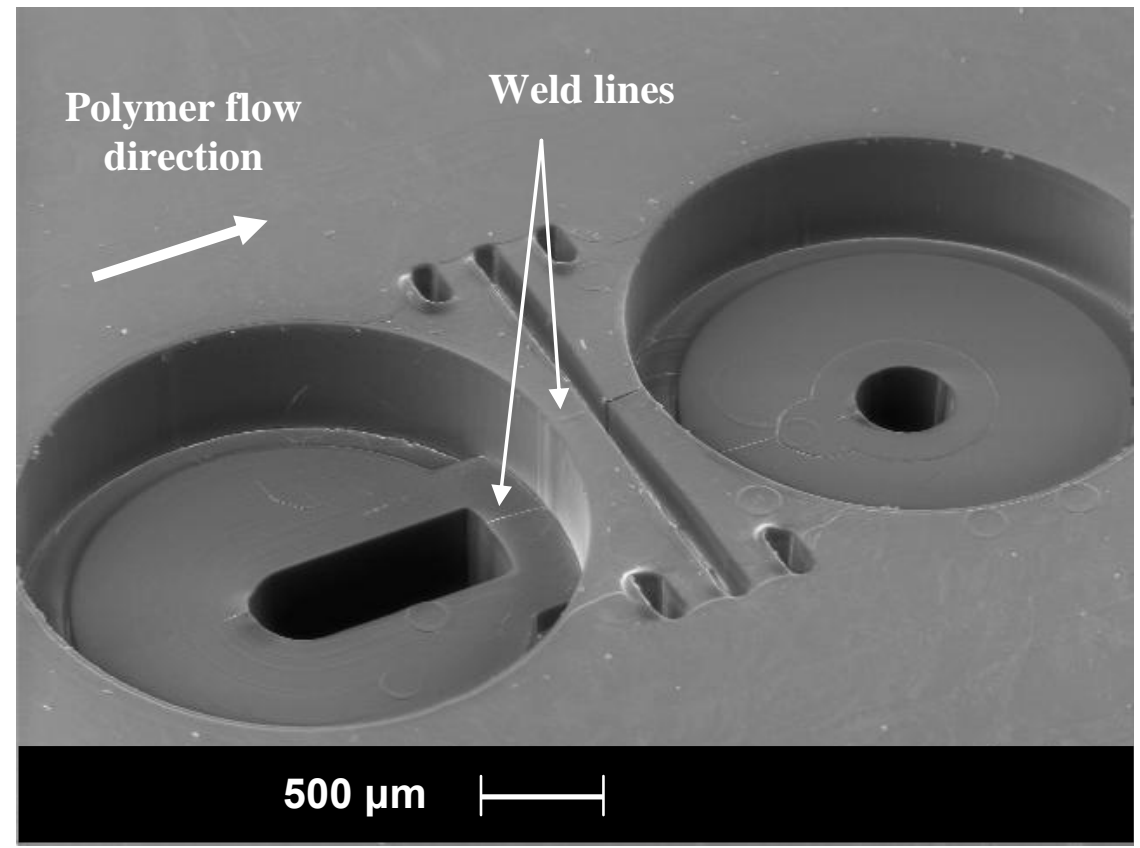

Figure 9. An SEM micrograph of the PMMA substrate

Figures 10 and 11 show images of the top view of the hybrid component and an SEM micrograph of the overmoulding, respectively. 


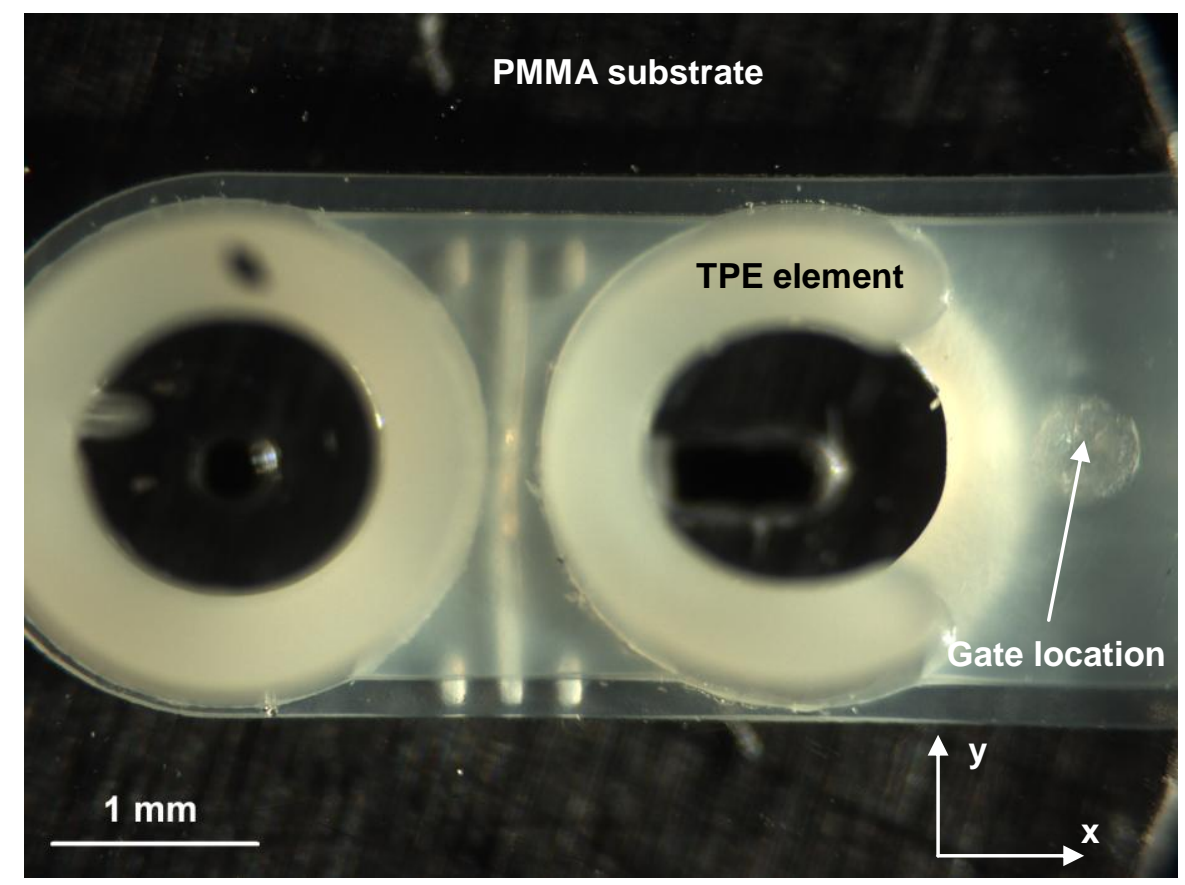

Figure 10. A top view of the PMMA-TPE hybrid component

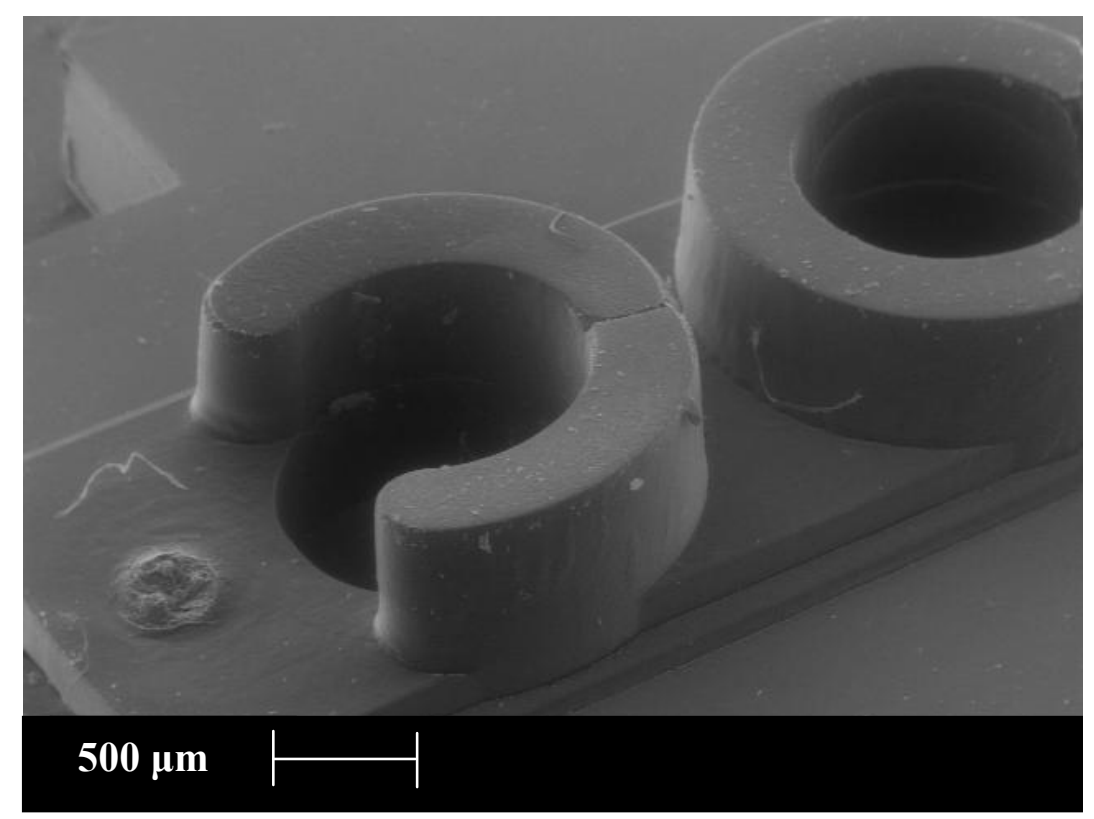

Figure 11. An SEM micrograph of the hybrid structure

Figrue 9 shows a complete filling of all the features by PMMA. Figure 10 shows a filled overmoulded structure, where it is noted from figure 10 that there is a misalignment in the $y$-direction by approximately $200 \mu \mathrm{m}$. This misalignment was measured using a measurement software integrated to an optical microscope. The misalignment was observed in all the produced parts within a variation of $\pm 2 \mu \mathrm{m}$. 
As a preliminary leakage test, the hybrid component was joined to a PMMA substrate with a single microfluidic channel. The system was tested with water-diluted ink at a number of flow rates starting with $0.32 \mathrm{ml} / \mathrm{min}$ (the flow rate at which plasma separation takes place with diluted blood) up to double this value. The corresponding pressure at maximum flow rate was measured using a digital pressure transducer and was approximately 300 mbar, where no leakage was observed. Some leaked droplets started to appear between the tube and the port at a flow rate of approximately $1.2 \mathrm{ml} / \mathrm{min}$ and pressure value of approximately 450 mbar.

The leakage was inspected visually using a magnifying device, where a coloured fluid was used to detect possible leakage. The tubes used were standard 1/16" tubes (approximately $1.6 \mathrm{~mm}$ outer diameter and $700 \mu \mathrm{m}$ inner diameters). Tubes were manually press-fitted into the rubbery ports, and no leakage was observed in the selected flow rate range. Figure 12 shows the testing setup.

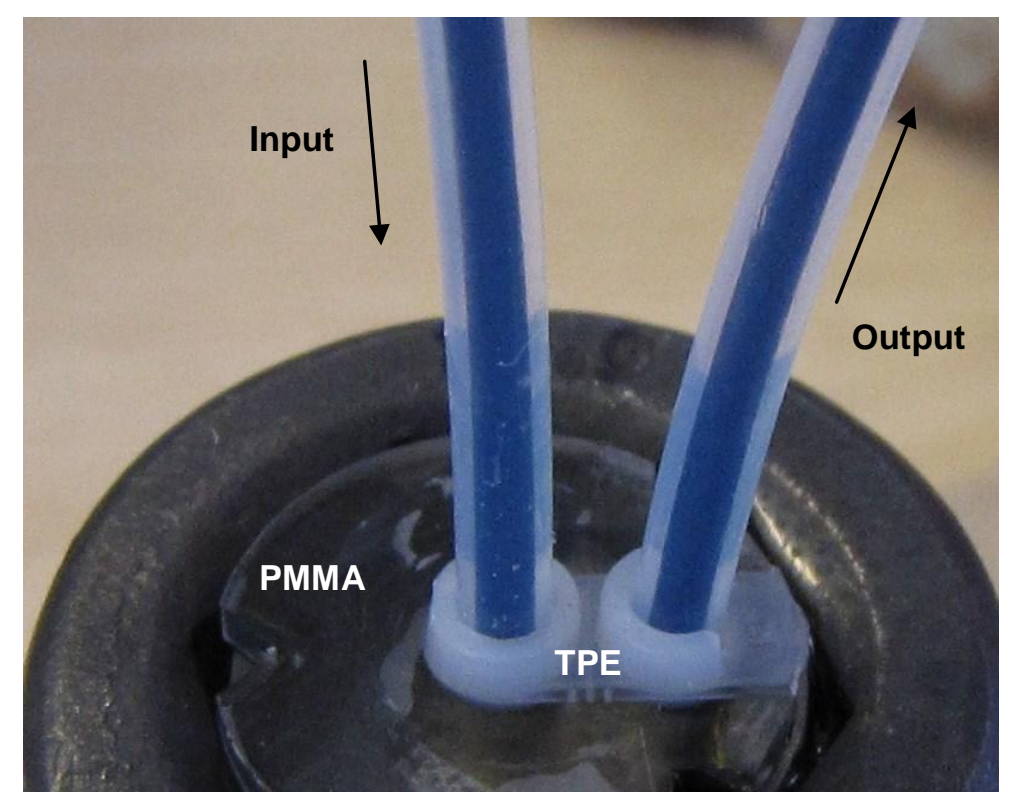

Figure 12. A leakage test with water-diluted black ink

\section{Discussion}

This paper presented a novel process chain for functional integration in $\mu \mathrm{IM}$. The approach was based on micro-overmoulding of TPE using a 3-plate mould with a replaceable insert. The approach used depended on developing a hybrid structure that benefited from different polymer properties. PMMA was used as a low-shrinkage, rigid and transparent polymer for the microfluidic substrate, whilst TPE was used as a low-tensile-modulus polymer for interconnect fittings. The low tensile modulus gave the polymer the rubbery performance that enabled the ports to mechanically grip the tubes without the need of extra adhesive. This rubbery grip made it easy to manually fit the tubes into the ports and, at the same time, prevented leakage from the ports. The process chain involved two 
main steps: mould manufacturing and replication, where the latter was done through two moulding stages.

\subsection{Mould microfabrication}

Concerning mould manufacturing, micro-milling was used to machine the features of the reconfigurable moulds: 2-plate and 3-plate moulds. For the 2-plate mould, figures 5, 7 and 8 showed that micromilling was suitable for producing the required features within specified tolerances using roughening and subsequent finishing stages. The micro-milling process used Tungsten-carbide cutters with diameters down to $100 \mu \mathrm{m}$.

However, the figures also show some of the micro-milling limitations, such as irregular surface finishes and burrs, for example figure 5. Burrs can sometimes be reduced, although not completely eliminated, by controlling the cutting parameters during the finishing stage in micromilling. Another approach is to remove burrs by post processing using, for example, ultrasonic wet peening [13]. In this particular experiment, no post processing was used to remove burrs, since their existence did not affect the application of the device.

In addition to burrs, micro-milling cutters have limitations in terms of their cutting length relative to their diameter. Bespoke cutters with extended cutting lengths were used to machine some features to the required depth.

When it comes to mould life expectancy, many factors affect the number of parts that can be produced before the feature-carrying insert needs to be replaced. In injection moulding, the mould life cycle depends on different parameters, including mould material, number of cavities, treatment of cavity surfaces, type of gate used and dimensional tolerances. Other factors are related to processing conditions, such as machine size and applied pressures and temperatures. The polymeric material itself affects the mould life cycle as some materials, especially glass-reinforced grades, have inherent abrasiveness. In conventional injection moulding, a typical mould life cycle would be in the order of magnitude of $10^{5}$ cycles. For micro-injection moulding, where requirements for reproducibility and tolerances are relatively stringent, the mould life cycle would expectedly be of fewer cycles, depending on the factors mentioned above.

\subsection{Replication by $\mu I M$}

With regard to replicating the PMMA substrate, figures 9 showed a complete replication of all the substrate features, including the channels that had an aspect ratio of 2 . A weld-line could also be observed along the centreline of the features.

Concerning the micromoulding of TPE, figure 10 shows that TPE completely filled the cavities around the cores, leaving the required space for tubes to be fitted as shown in figure 11. This shows the feasibility of using TPEs in micromolding of relatively high-aspect ratio applications. 
Filling high aspect ratios by $\mu \mathrm{IM}$ is usually affected by the material properties, the geometric configuration (e.g. gate location) and the process conditions [14]. With regard to material properties, it is recommended to select polymers with high melt-flow index (MFI) so that the polymer melt can easily flow into micro-sized cavities. The used TPE had an MFI of 3, which is relatively low, because most available elastomer grades had relatively low MFI.

With regard to geometric configuration, the design of the mould and the scale of the features did not allow for alternative locations for the gate other than the place shown in figure 8 . The remaining method to fill the high-aspect-ratio features was to control the process conditions. Previous work showed that increasing melt temperature and injection speed improves filling mould cavities in $\mu \mathrm{IM}$ for different polymers [14-16]. In this experiment, as shown in table 1, the melt temperature of the TPE was $200^{\circ} \mathrm{C}, 20$ degrees above the recommended value by the manufacturer. The injection speed was raised to a relatively high value of $200 \mathrm{~mm} / \mathrm{s}$. These two conditions, combined by a relatively high holding pressure, ensured the complete filling of the cavities.

The use of the 3-plate mould offered the advantages of automatic separation of gates and the existence of features on both sides of the mould cavity.

With regard to material selection, the TPE element adhered to the PMMA substrate, because the selected TPE grade had adhesion compatibility with polar polymers, such as PMMA. The microchannels that were replicated into the PMMA substrate provided extra mechanical interlocking between the TPE element and PMMA. In addition to adhesion compatibility, other aspects should be considered when selecting polymers for integration by micro-over moulding. For example, it is recommended to use polymers with relatively high melt-flow-index values to assist in filling microscale cavities. In addition, the thermal properties of the two polymers should be selected such that the overmoulded material does not affect the features of the substrate polymer. The former should, therefore, have a lower softening temperature than the latter. If the device is intended to be used for a biological application, like the case of this paper, the compatibility of the selected materials with biological applications is essential for the device functionality. Other material properties, such as optical transparency, resistance to UV light, etc. might also put limitations on the selected materials.

A unidirectional shift of approximately $200 \mu \mathrm{m}$ was, however, observed between the PMMA and the TPE layer. This repeated unidirectional shift in the produced parts indicates the existence of a misalignment between the moving plate and the third plate. This misalignment is associated with the wear of some of the dowel pins that are responsible for aligning the two mould plates together. The wear in the dowel pens results in gaps around the pins that affects the alignment accuracy. The shift in the resulting hybrid structure did not affect the functionality in this particular case, since it did not block the microfluidic channels. However, for application with tighter tolerances, further positioning calibration would be required between the mating plates of the mould by, for example, replacing the worn dowel pins. 
In addition to mould positioning, two areas of improvement would be useful to achieve a well established process. Firstly, the runner system should be redesigned to decrease its volume relative to the parts. Figure 13 shows the relative size of the runner system with respect to the replicated parts. This is a typical challenge in $\mu \mathrm{IM}$, where runners consume a large volume fraction of processed material per shot. Another alternative would be to increase the number of cavities in the mould to produce more parts per shot.

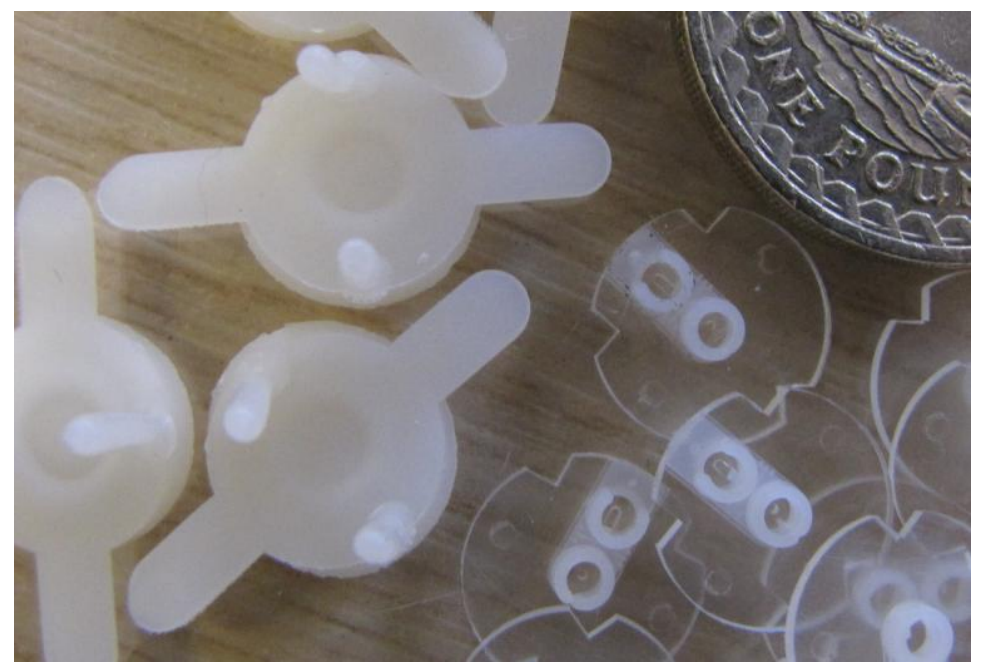

Figure 13. Runner systems compared to replicated parts

Initial leakage tests were conducted using water-diluted ink, where no leakage was observed in the flow rate range between 0.32 and $0.62 \mathrm{ml} / \mathrm{min}$, which is the range at which blood/plasma separation takes place. This corresponded to a pressure of approximately $300 \mathrm{mbar}$. This indicated that the TPE ports were efficiently gripping the tubes up to approximately 450 mbar, when leakage started to appear.

A mass-manufacturing consideration of the presented process chain is the ability to automate the process, such that 2-component integration is done in a single stage. One approach to automation is the use of two-component machines, commonly used in conventional moulding. Two-component micro-injection moulding machines have been recently introduced into the market, such as FormicaPlast 2K from DESMA [17].

\section{Conclusion}

This paper presented a process chain for integrating functional elements by microovermoulding. A hybrid structure was produced by micro-moulding TPE over PMMA to produce integrated interconnection ports. The process chain was based on using micromilling for producing micro-structured replaceable moulds, followed by replication with $\mu \mathrm{IM}$. A 2-plate mould was used for producing the PMMA substrate using a reconfigurable aluminium insert. A 3-plate mould with a 
replaceable insert was used to mould TPE over the PMMA substrate. The required cavities (AR of 2.6) for tube fittings were successfully produced. A shift of about $200 \mu \mathrm{m}$ was detected due to mouldhalves misalignment. This did not affect the functionality of the system since it was within acceptable tolerance. A leakage test showed that the system was leak-proof within a range of flow rates between 0.32 and $0.62 \mathrm{ml} / \mathrm{min}$.

\section{References}

[1] Attia UM, Marson S, Alcock JR. Micro-injection moulding of polymer microfluidic devices. Microfluid. Nanofluid. 2009; 7 (1): 1-28.

[2] Attia UM, Alcock JR. Integration of functionality into polymer-based microfluidic devices produced by high-volume micromoulding techniques. Int. J. Adv. Manuf. Technol. 2009. In Press. DOI: 10.1007/s00170-009-2345-8.

[3] Michaeli W, Ziegmann C. Micro assembly injection moulding for the generation of hybrid microstructures. Microsyst. Technol. 2003; 9 (6-7): 427-430.

[4] Michaeli W, Rogalla A, Ziegmann C. Processing technologies for the injection moulding of hybrid microstructures. Macromol. Mater. Eng. 2000; 279: 42-45.

[5] Michaeli W, Kamps T. Micro assembly injection moulding with plasma treated inserts. Microsyst. Technol. 2008; 14 (12):1903-1907.

[6] Piotter V, Prokop J, Ritzhaupt-Kleissl H-J, Ruh A, Hausselt J. Multi-component microinjection moulding-trends and developments. Int. J. Adv. Manuf. Technol. 2009: 1-9.

[7] Yoon S-H; Alabran M, Lee J, Mead J, Barry C, Carter D. Micro-injection molding of high aspect ratio features with thermoplastic polyurethanes. Proceedings of the Annual Technical Conference, (ANTEC 2007); 6-11 May 2007.

[8] Van der Beek M, Mathew A, Andreadaki A, Kieft I, Nellissen T, Weekamp W. Development of integrated microfluidic devices - Packaging and interconnect solutions. Mstnews 3/09; June 2009. [9] Zhao J, Mayes R, Chen G, Xie H, Chan P. Effects of process parameters on the micro molding process. Polym. Eng. Sci. 2003; 43 (9): 1542-1554.

[10] Zhao J, Mayes R, Chen G, Chan PS, Xiong ZJ. Polymer micromould design and micromoulding process. Plast. Rubber Compos. 2003; 32 (6): 240-247.

[11] Becker H, Gärtner C. Polymer microfabrication technologies for microfluidic systems. Anal. Bioanal. Chem. 2008; 390 (1): 89-111.

[12] Marson S, Attia UM, Allen DM, Tipler P, Jin T, Hedge J and Alcock JR. Reconfigurable micromould for the manufacture of truly 3D polymer microfluidic devices. Proc. CIRP Design Conf. Cranfield, UK, 30-31 March 2009: 343-346. 
[13] Kienzler A, Hoffmeister J, Schulze V. Surface finishing of micro mould inserts made of precipitation-hardened steel. 4M/ICOMM 2009 - The Global Conference on Micro Manufacture 2009; 237-240.

[14] Sha B, Dimov S, Griffiths C, Packianather MS. Investigation of Micro-Injection Moulding: Factors Affecting the Replication Quality. J. Mater. Process. Technol. 2007; 183 (2-3): 284-296. [15] Pirskanen J, Immonen J, Kalima V, Pietarinen J, Siitonen S, Kuittinen M, Mönkkönen K, Pakkanen T, Suvanto M, Pääkkönen EJ. Replication of sub-micrometre features using microsystems technology. Plast. Rubber Compos. 2005; 34 (5-6): 222-226.

[16] Sha B, Dimov S, Griffiths C, Packianather MS. Micro-injection moulding: Factors affecting the achievable aspect ratios. Int. J. Adv. Manuf. Technol. 2007; 33 (1-2): 147-156.

[17] DESMA TEC. Micro injection moulding machine for smallest shot weights. 2009; Available at: http://www.desma-tec.de/en/machines/micro_injection/micro_injection.html. Accessed 2009. 